\title{
DANÇA ALÉM DA VISÃO: POSSIBILIDADES DO CORPO CEGO
}

\author{
Clotildes Maria de Jesus Oliveira Cazé
}

Mestra em Dança pelo PPGDança da Escola de Dança da UFBA (2008), Especialista em Ginástica Rítmica pela UNOPAR (2003) e em Psicopedagogia pelo CEP/MEx/UFRJ (1998). Graduada em Educação Física pela UCSal (1982).

Adriana da Silva Oliveira*

Graduada em Fisioterapia pela Escola Bahiana de Medicina e Saúde Pública (2004) e mestranda em Dança pelo PPGDança da Escola de Dança da UFBA (2008).

\begin{abstract}
Resumo
O artigo suscita reflexões sobre as possibilidades do corpo cego e a interação com a dança na construção da autonomia. Autores como Fleming, Frazão e Lusseyran apontam questões sobre a rede tecida pelos sentidos na formação de imagens sensório-motoras pelo deficiente visual. Damásio contribui para o entendimento de emoção e razão. Llinás explica a construção do movimento baseado na Neurociência. Katz traz a Teoria do Corpomídia para pensar a dança como cognição. Nas considerações finais, observamos a dança como parte do conhecimento humano e espaço que possibilita o entrelaçamento de saberes, haja vista o ser humano se construir em rede pelo imbricamento entre corpo, ambiente e cultura.
\end{abstract}

Palavras-chave: deficiência visual - movimento - corpo - dança - autonomia

Além desse ver eu preciso enxergar, mas para enxergar eu preciso do olhar dos meus olhos? [...] Se elaboro bem as minhas sensações e emoções corporais, não preciso só dos meus olhos, mas do meu corpo para olhar, ver e enxergar. (SANTOS, 1996, p. 78).

\section{Introdução}

$\mathrm{H}$ abitamos em um mundo predominantemente visual. Imagine a importância da visão para o ser vivo que necessita perceber o mundo a fim de interagir com ele e poder se mover. Como se deslocar em segurança por este lugar "estranho", "inóspito", "perigoso", sendo este ser desprovido da principal fonte de percepção humana: a visão? Ser cego é ter a percepção de um mundo borrado, sem contornos nítidos, sem definições. É não poder contar com o recurso da visão para conhecer o mundo no qual se vive. Os olhos são tão importantes para os seres humanos que ao se referir a algo que tem a nossa atenção e cuidado, costuma-se dizer que é a nossa "menina dos olhos".

E por que existem seres humanos cegos? Alguns com cegueira total e outros com cegueira parcial. Qual o motivo desta diferença? Onde encontrar as explicações para estes fatos? Estas pessoas não são boas o suficiente e receberam um castigo "divino"? Ou é um ser estranho que vem de fora e arranca os olhos e a capacidade de visão dessas pessoas como no conto - "O estranho" - relatado por Freud (1976, p. 289), no qual "O Homem de Areia é um ser perverso que chega quando as crianças não vão para a cama e joga punhados de areia nos olhos delas, de modo que estes saltam sangrando da cabeça".

Que ser estranho é este que tem a possibilidade de provocar deficiências, de interferir nas ações dos seres humanos, tornandoos reféns das circunstâncias? É possível, por analogia, compreender este ser estranho, o 
"Homem de Areia" que arranca os olhos das crianças, como os acidentes e as enfermidades tipo diabetes - que podem ocorrer e provocar cegueira, interferindo na qualidade de vida desses indivíduos.

Existem dois tipos de cegueira: congênita e adquirida. $\mathrm{O}$ primeiro tipo se refere às pessoas que já nascem sem o recurso da visão; elas não possuem imagens pré-formadas, inclusive a imagem corporal de si mesmo. $\mathrm{O}$ segundo tipo se refere às pessoas que perderam a visão em algum momento da vida por causas diversas; possuem imagens mentais anterior à deficiência. Além disso, a cegueira pode ser total ou parcial; na cegueira parcial, o indivíduo apresenta visão subnormal.

Provavelmente, de todas as deficiências que afetam os seres humanos, a que mais priva o indivíduo do contato com o mundo externo é a deficiência visual, visto que o olho é o maior captador de imagens sensório-motoras. Os "olhos roubados" impossibilitam que esses indivíduos possam perceber e compreender o mundo no qual estão inseridos. Eles necessitam de artefatos que ampliem as suas possibilidades de entender o mundo. Mas, esta deficiência não é algo que veio de fora, de um mundo fantástico, etéreo, como no conto de Freud (1976, p. 288), um mundo "povoado de espíritos, demônios e fantasmas”.

Essa deficiência pode estar na formação do ser, nas explicações biológicas, nas doenças adquiridas ou nos acidentes que podem acontecer ao longo da vida; daí Freud (1976, p. 289) afirmar que "o medo de ferir ou perder os olhos é um dos mais terríveis temores das crianças. Muitos adultos conservam uma apreensão nesse aspecto e nenhum outro dano físico é mais temido por esses adultos do que um ferimento nos olhos". Freud (1976) assegura que a ansiedade quanto aos próprios olhos e o medo de ficar cego se relacionam ao temor de ser castrado.

O corpo cego, assim como qualquer outro corpo, possui uma história pessoal. Ele é constituído de movimento, pensamento, emoção, razão, sentimentos e sonhos, muitos sonhos. As vias de acesso a estas informações é que são outras, pois eles não utilizam a visão. Damásio (1996) afirma que sentimentos e emoções são percepções diretas de nossos estados corporais e constituem um elo essencial entre o corpo e a consciência, estando relacionadas com o processo de tomada de decisão.

O movimento é a nossa primeira forma de linguagem: uma linguagem não verbal estruturada no corpo. Partindo desta idéia, o corpo é a condição primeira para que ocorra o pensamento a partir da articulação entre a coerência e a coesão das ações sensório-motoras.

O corpo testa hipóteses de movimentos e seleciona os mais eficientes. Pelo processo de memória e repetição promove a aprendizagem desses movimentos em uma negociação com o ambiente, organizando a informação em tempo real. Ocorre um mapeamento temporal, a informação que chega ao cérebro se reconfigura a todo o momento pelo acesso às novas informações, facilitando a configuração rápida de imagens. A imagem sensório-motora, segundo Llinás (2002), necessita de uma pré-alimentação e uma retro-alimentação da informação.

A limitação do indivíduo cego está relacionada à percepção visual; entretanto suas outras fontes de percepção estão intactas e possibilitam a aprendizagem. Aqui a regra válida é que cada indivíduo tenha a possibilidade de explorar o ambiente, buscando novas formas de interação, ampliando suas capacidades multissensoriais para uma aprendizagem significativa, reorganizando os conhecimentos pela interação dos sentidos não comprometidos.

O desenvolvimento da competência sensório-motora ocorre ao longo da vida, não se restringe apenas ao período da infância (LAKOFF; JOHNSON, 1999; LLINÁS, 2002). Este fato reforça a importância da prática da dança mesmo na vida adulta. Para os indivíduos cegos, esta prática torna-se ainda 
mais relevante pelas interações espaço/temporais e corporais com os processos mentais. Os processos de assimilação, organização, reorganização e acomodação das experiências vividas pelos indivíduos cegos ocorrem de forma mais lenta do que nos indivíduos normovisuais, ${ }^{1}$ entretanto, eles acontecem.

Frazão (1968) afirma que a audição e o tato possuem grande importância nas elaborações mentais do indivíduo cego. Também o aparato proprioceptivo é requisitado para o controle postural e a manutenção do equilíbrio. Sobre esta questão, é necessário compreender que:

Postural stability is essential in the everyday activities involved in leading an independent lifestyle. [...] The ability to modulate posture and voluntary movement serves to enhance the acquisition of environmental information, not only from visual mechanisms but also from somatosensory and vestibular mechanisms ${ }^{2}$ (WADE; JONES, 1997, p. 620-621).

A dança apresenta esta possibilidade, pois além de trabalhar aspectos que envolvem a construção do pensamento, a criatividade e as idéias de tempo-espaço, melhora a manutenção do equilíbrio e da postura corporal. É necessário entender que as capacidades e habilidades do indivíduo cego não estão limitadas; a organização perceptiva é que se processa de maneira diferente devido à ausência da visão.

Praticar dança permite ao indivíduo cego construir suas próprias idéias de tempo /espaço, de manutenção do equilíbrio pela reorganização postural, a partir da utilização dos outros sentidos, do aparato vestibular e da propriocepção. O indivíduo estabelece seu

1 Normovisuais: pessoas com visão dentro do padrão de normalidade.

2 Tradução das Autoras: Estabilidade postural é essencial nas atividades diárias envolvidas em guiar um estilo de vida independente. [...] A habilidade para modular a postura e os movimentos voluntários serve para intensificar a aquisição da informação ambiental, não somente a partir de mecanismos visuais, mas também a partir dos mecanismos somatossensórios e vestibular. ritmo próprio de aprendizagem através da experimentação, do contato corporal, do toque, da exploração do espaço e dos sons. Os conhecimentos produzidos nestas experimentações são levados para as atividades da vida diária.

A dança, para o deficiente visual, possibilita a superação de limites impostos pela cegueira, ampliando as possibilidades motoras com a execução de movimentos conscientes. Ela promove a melhoria do equilíbrio e da locomoção; da socialização, da realização pessoal e propicia uma vida ativa; além disso, a dança aumenta a compreensão da noção espaço/temporal e a noção de consciência corporal pela concretização da imagem de si mesmo, podendo ser um espaço de descobertas e consolidação de novos padrões motores que possibilitam novas aprendizagens e a aquisição da autonomia.

A aquisição do movimento em dança pelo indivíduo cego depende das condições oferecidas pelo meio e pelo grau de apropriação que o corpo fizer destas ações pela percepção, estabelecendo relações entre as sensações e os movimentos elaborados. Isso possibilita ao indivíduo prever mentalmente atos motores cada vez mais complexos, sendo o corpo co-participativo na construção desse conhecimento.

Piaget (1964) defende a idéia de que o conhecimento é fruto de construções sucessivas com elaborações constantes de novas estruturas. Este pensamento nos remete a Katz (2005) quando a autora afirma que a cada vez que realiza um mesmo movimento, o mapa neuronal já não é o mesmo, pois este acontece no tempo/espaço do acontecimento real. Sendo assim, quando o indivíduo se depara com novas situações, seja ele cego ou não, utiliza esquemas de ações sensório-motoras disponíveis para a percepção, construção e assimilação do movimento no momento em que o mesmo acontece.

Lakoff e Johnson (1999) ratificam este pensamento quando afirmam que todas as informações que chegam ao corpo via percepção são sensório-motoras. Ocorre uma formação 
de redes neuronais, um criterioso trabalho de seleção de informação em rede pela capacidade de neuroplasticidade ${ }^{3}$ do cérebro.

O indivíduo não armazena as informações, seja em um corpo cego ou não; elas são refeitas a cada momento sempre que necessárias, apoiando-se no real, nas conexões entre o mundo externo e o aparato cerebral. Desse modo a aprendizagem é construída no fazer concreto, na manipulação, na locomoção, representando internamente a realidade (LLINÁS, 2002).

$\mathrm{O}$ indivíduo cego não tem a possibilidade de receber as informações do mundo externo através da visão. De que forma então pode ser percebida a informação dança pelo deficiente visual? Este corpo cego percebe a dança da mesma forma que os indivíduos normovisuais percebem?

Nesta perspectiva, a motivação é um fator intrínseco relevante no processo ensinoaprendizagem da dança, pois mobiliza e impulsiona o indivíduo, predispondo-o a agir para alcançar os seus objetivos e a buscar soluções para resolver os problemas. A motivação aliada à curiosidade são as molas propulsoras na descoberta das possibilidades do corpo. Utilizando a percepção e a reflexão, ocorre a assimilação dos movimentos da dança pela representação construída mentalmente, permitindo ao cego, como lembra Lusseyran (1995, p. 44), "mergulhar numa vida que é tão real e difícil quanto às outras vidas", mas que vale a pena ser vivida.

De acordo com Fleming (1978, p. 109): "a criança cega terá dificuldade com tarefas cognitivas e perceptivas caso não obtenha uma vasta gama de experiências e oportunidades de explorar seu ambiente". A dança possibilita esta exploração e o aumento deste repertório de experiências e oportunidades pela utilização do sistema somatossensorial, aguçando os sentidos tátil, auditivo e cinestésico.

3 Neuroplasticidade do cérebro: capacidade de adaptabilidade a novas situações.
Quanto maior for o tempo de exploração do movimento individual ou na relação com o outro, maior será a compreensão e a assimilação deste movimento, facilitando o entendimento do tempo/espaço, das noções de lateralidade, da aquisição do equilíbrio e do controle postural, além da melhoria da mobilidade. Refina também a idéia de corpo nas inter-relações com os outros e com o ambiente.

Golomer et al. (1999) e Vuillerme et al. (2001a apud NAGY et al., 2004) afirmam que: "It has been observed that professional dancers and gymnasts are significantly more stable and less dependent our visual for postural control that untrained subjects ${ }^{\prime \prime}$. Se este fato é observado nos indivíduos normovisuais que praticam dança, apresentando resultados significativos; por analogia, é possível compreender que para o indivíduo cego a prática da dança possibilita esta estabilidade no controle postural, melhorando a sua mobilidade e conseqüente autonomia.

Nowill (1996) garante que o maior desejo do indivíduo cego é poder participar da vida em sociedade. Para que isto ocorra é necessário promover ações que possibilitem a sua autonomia. Ele necessita pegar, manipular e sentir, a fim de perceber a realidade concreta. Para facilitar este processo é necessária a interação dos sentidos, facilitando a percepção e conseqüente aprendizagem.

Muitas são as tentativas de melhorar a qualidade de vida das pessoas portadoras de deficiências. Estas ações permitem a participação destes corpos na sociedade, possibilitando uma interação entre os sujeitos e se não for possível a superação, pode auxiliar na convivência com a deficiência, buscando promover a autonomia desses indivíduos. Os deficientes não necessitam da compaixão dos não-deficientes; eles necessitam de espaço na

\footnotetext{
4 Tradução das Autoras: Tem sido observado que dançarinos profissionais e ginastas são significativamente mais estáveis e menos dependentes da visão para o controle postural que sujeitos não treinados.
} 
sociedade da qual fazem parte. Não se trata aqui de assistencialismo e sim de oportunidades para que eles exerçam o seu papel de cidadão. Este fato inclui a possibilidade de participar de atividades que, a princípio, $\mathrm{pa}^{-}$ recem impróprias para o deficiente. A dança é um exemplo.

A compreensão deste fato permite que esses indivíduos sejam inseridos no campo artístico, cultural, educacional, político e social pelo acesso à prática destas atividades individualmente ou em grupos. Entretanto, muitas são as dificuldades encontradas por estes corpos deficientes: profissionais despreparados, espaços inadequados e falta de oportunidade são alguns exemplos. No caso do deficiente visual, as dificuldades aumentam sobremaneira pela impossibilidade de utilizarem a capacidade antecipatória do cérebro de prever situações e saber solucioná-las adequadamente. Isto se dá pela ausência da visão que é a responsável pela pré-alimentação das respostas motoras (LLINÁS, 2002).

Bobath (1978) ratifica esta idéia ao afirmar que o sentido da visão dá acesso às informações do mundo externo, sendo o principal sentido utilizado na formação de imagens sensóriomotoras. A partir destes dados indagamos: É possível o corpo cego se apropriar da informação dança? Como este fato se processa?

\section{Dançar sem olhos}

Sabemos que a aquisição e construção dos movimentos acontecem a partir da percepção sensorial, sendo o sistema visual o principal responsável por este fato. Que recursos os deficientes visuais utilizam para elaborar os movimentos e transformá-los em dança sem ter o referencial do mundo externo? Como esta experiência se dá sem a presença de movimentos visualizados para serem entendidos?

Para entender esta experiência é preciso pensar a dança no momento em que ela acontece, pois Llinás (2002) assegura que o pensamento é a interiorização evolutiva do movimento. Para Katz (2005), a dança é uma forma de pensamento. Sendo a dança movimento, estas idéias se complementam.

\begin{abstract}
A dança nasce quando no corpo se desenha um determinado tipo de circuitação neuronial/ muscular. Este mapa, exclusivamente ele, tem o caráter de um pensamento. Quando ele se dá a ver no corpo, o corpo dança. Esse momento parece inaugural. No entanto, o apresentar-se da dança no corpo já representa o fim de um caminho. Quando lá se instala, a dança inaugura uma outra cadeia de circuitação para o corpo. Os acionamentos que impelem esse trânsito têm o mesmo caráter daquele que ocorre no cérebro humano (KATZ, 2005, p. 52).
\end{abstract}

Para compreender a dança, os indivíduos cegos necessitam vivenciar experiências corporais que possibilitem o contato com o mundo e com os outros. Llinás (2002) afirma que "mirar é uma forma sutil de tocar"; observando esta idéia é possível pensar que na ausência da visão "tocar é uma forma diferente de ver"; isto é, utilizar a audição para "sentir" o ritmo e o tato para "perceber" o movimento e a relação com o corpo.

Os seres humanos são modulados pelos sentidos para se relacionar com o mundo a sua volta. A visão é a principal via de recepção das imagens que possibilitam a nossa compreensão de mundo; os deficientes visuais não possuem esta via. Para compreender o que é um mundo sem imagens, podemos fechar os olhos e imaginar, tentar nos locomover em um espaço desconhecido sem o uso de artefatos que ampliem a nossa possibilidade de visão. Ainda assim somos privilegiados, pois já conhecemos o mundo externo e temos a idéia destes fatos que podem ser recuperados pela evocação das memórias já experenciadas.

A bengala de Hoover ${ }^{5}$ é um artefato que "expande a visão" do deficiente visual, aumen-

5 O Primeiro Tenente Oftalmologista Richard Hoover, após a segunda Guerra Mundial, se propôs a estudar e tratar o problema da cegueira e o mecanismo da marcha e criou um método revolucionário de locomoção, usando um instrumento que lembrava um bastão, mas com função, material 
tando a distância entre este e os objetos que o cercam, proporcionando-lhe uma maior autonomia. Merleau-Ponty (1994, p. 198) explica que "a bengala para o cego não é um simples objeto, sua extremidade é uma zona sensível que aumenta a amplitude e o raio de ação de tocar, semelhante a um olhar”. Ela é um instrumento de orientação e promove a autonomia do indivíduo cego, funcionando como uma extensão do próprio corpo. Esta idéia nos reporta a pensamentos já cultivados no Renascimento:

[...] vê tudo em relação e procura(r) correspondência entre corpo, natureza e instrumentos. São metáforas que se enviam reciprocamente pelos parâmetros comuns percebidos nessas três instâncias. Por isso, seu mecanicismo é metafórico e procura sempre associar máquinas a modelos, figuras, organismos e necessidades práticas humanas. Ele vê os instrumentos como extensão das capacidades do organismo humano de pôr-se em relação com o mundo e utilizá-lo (BRANDÃO, 2004, p. 278).

Ainda Brandão (2004, p. 279) lembra que "para Alberti, a máquina é produto da história humana e metáfora que multiplica as possibilidades de todo nosso ser. [...] Alberti humaniza a máquina e a coloca em função dos fins humanos".

A dança para o deficiente visual deve ser uma experiência na qual ocorra uma interação e um compartilhamento de informações em nível de pele pelo toque, pelo sentir das características de outros corpos. É possível afirmar que são corpos que se comunicam. Hellen Keller, cega e surda desde bebê, reforça a necessidade do toque das mãos para o desenvolvimento da percepção de mundo do indivíduo cego:

Não posso desfrutar da beleza do movimento rítmico senão numa esfera restrita ao toque de minhas mãos. Só posso imaginar vagamente a

e comprimento diferentes. Este instrumento recebeu o nome de Bengala de Hoover.

Disponível em: <http://intervox.nce.ufrj.br/ãmigosbr/historia.html>. Acesso em: 15 dez. 2006. graça de uma bailarina, como Pavlova, embora conheça algo do prazer do ritmo, pois muitas vezes sinto o compasso da música vibrando através do piso. Imagino que o movimento cadenciado seja um dos espetáculos mais agradáveis do mundo. (HELLEN KELLER ${ }^{6}$ ).

Possibilitar aos deficientes visuais o contato com a dança é uma forma de ajudá-los a sentir, perceber, conhecer e aprender. Além disso, vivenciando a dança, esses indivíduos têm a possibilidade de utilizar suas capacidades, descobrir suas habilidades e explorar suas potencialidades, aumentando a sua autonomia.

Dançar é movimentar-se. No caso do indivíduo cego é "ver" com o corpo o que os olhos não podem enxergar; é ultrapassar limites impostos pela deficiência visual. É aprender a partir da experiência em tempo real, sendo a imagem sensório-motora uma realidade produzida pela interação das percepções no aparato cerebral. A formação da imagem corporal no indivíduo cego depende de informações táteis, auditivas e cinestésicas já que as experiências visuais são limitadas, dificultando-lhe a percepção do mundo.

A imagem corporal e a relação desta com o espaço circundante elaborada pelo corpo cego, possivelmente, apresentam fronteiras borradas por o indivíduo não ter a percepção visual dos objetos e do seu próprio corpo. $\mathrm{O}$ contato com o outro nas aulas de dança facilita este processo, uma vez que o leva a perceber o movimento que o outro realiza, permitindo reconhecer o movimento do próprio corpo e expor idéias corporalmente, se apropriando de parâmetros sensório-motores relacionados à marcha, ao equilíbrio, à força, à flexibilidade e ao tônus muscular.

6 Três dias para ver - Ensaio escrito por Hellen Keller e publicado na revista Seleçôes Reader's Digest há 70 anos. Reeditado em Seleçôes Reader's Digest em junho de 2002.

Disponível em: <http://www.cerebromente.org. br/n16/curiosidades/helen.htm>. Acesso em: 15 nov. 2006 
O deficiente visual constrói o seu universo a partir do toque e os seus movimentos em dança serão construídos a partir do seu repertório de experiências. Poder movimentar-se sem o auxílio de outras pessoas é, para o deficiente visual, sinônimo de autonomia conquistada passo-a-passo em um processo contínuo de novas adaptações, promovendo novas aprendizagens. Desta forma, dançar não deve ser um ato mecânico destituído de significado para o corpo que dança. As atividades de dança para os deficientes visuais devem ser criativas, lúdicas, com movimentos que promovam a autonomia deste corpo.

A dança pode ser construída a partir dos movimentos cotidianos, das atividades da vida diária e da locomoção, promovendo autonomia. Com isso há um ganho na qualidade de vida, possibilitando a inserção sócio-cultural do indivíduo cego na comunidade como um cidadão ativo e capaz. Desse modo, a dança não deve estar presa a valores e modelos preestabelecidos e deve permitir que o indivíduo descubra nos movimentos o seu fazer com estilo e caráter próprio; fato que o individualiza. Além disso, ela deve ser desenvolvida juntamente com os indivíduos normovisuais promovendo assim a interação, pois, o movimento em dança também é coletivo.

Nesse sentido, a dança pode surgir a partir do jogo, da brincadeira, da atividade dirigida, da exploração de movimentos através do toque, da relação corpo-a-corpo, unindo emoção e razão. $\mathrm{O}$ indivíduo cego tem a possibilidade de explorar a sua criatividade e descobrir a sua potencialidade criadora, pois, como corrobora Llinás (2002; p. 198), “[...] a criatividade do cérebro humano, os processos neurais inerentes àquilo que chamamos de criatividade nada tem a ver com a racionalidade. [...]. A criatividade não nasce da razão".

A dança, para o corpo cego, deve ser pensada como movimento, corpo em ação, e não como terapia; pois a habilidade motora, uma vez adquirida, se consolida e isto leva a autonomia, diminuindo a ação dos fatores limi- tantes impostos externamente ao corpo cego. Se a dança é o pensamento do corpo, como afirma Katz (2005), cabe-nos perguntar: Qual a importância da dança na construção da autonomia do indivíduo cego? De que forma atua no desenvolvimento da percepção corporal deste corpo? Qual o significado da dança para estes corpos?

A dança para o deficiente visual pode significar a intermediação entre o seu corpo, o corpo do outro e o ambiente, permitindo-lhe ganhos na qualidade de vida como a melhoria da auto-estima, o equilíbrio, a manutenção postural e, principalmente, a autonomia. Neste processo, a dança deve ser valorizada porque através dela o indivíduo percebe o movimento em relação ao seu corpo e o corpo do outro; o seu espaço e o espaço do outro, e também a interação entre estes.

Acreditamos que a dança neste corpo privado de visão possibilita novas relações do sujeito que dança com o seu Umwelt ${ }^{7}$ e o ambiente. Santaella (2003, p. 184) lembra que "não vemos o mundo lá fora como algo separado de nós, mas vemos apenas aquilo que nossa organização sistêmica nos permite ver". Partindo desta idéia é possível afirmar que o indivíduo cego 'ver' aquilo que a união dos outros sentidos permite captar do mundo externo.

Assim como Alberti, citado por Brandão (2004) também Santaella (2003) reforça a idéia de ampliação das possibilidades do corpo pela presença de artefatos e da união de eventos que constituem a nossa humanidade:

Em um mesmo corpo, reúnem-se o mecânico
e o orgânico, a cultura e a natureza, o simula-
cro e o original, a ficção científica e a realidade
social. A declaração de Haraway de que somos
todos ciborgs deve ser tomada em sentido li-
teral e metafórico. No sentido literal, porque
as tecnologias biológicas e teleinformáticas

7 Umwelt: "Universo particular" ou "privado", proposto por Uexkull (1992) apud Vieira (2006). Percepção de um Universo que não é real, mas o que é permitido pela complexidade, produzido na interação com a realidade. 
estão, de fato, redesenhando nossos corpos. Metaforicamente, porque estamos passando de uma sociedade industrial orgânica para um sistema de informação polimorfo (SANTAELLA, 2003, p. 186).

O corpo do mundo contemporâneo tem sido redesenhado por tecnologias cada vez mais sofisticadas, tecendo uma rede complexa entre os eventos que constituem a nossa humanidade. Desta forma, corpos cegos que dançam também têm suas habilidades e competências redesenhadas pela possibilidade de utilização dessas novas tecnologias.

Nesta perspectiva, este corpo está sempre em um estado transitório de imagens e memórias experenciadas que se constituem no trânsito de informações entre corpo e ambiente, natureza e cultura. É um corpo ativo na ação cognitiva que está imbricado em um contexto cultural, social, imaginativo, desejante, passional e metafórico como esclarecem Lakoff e Johnson (1999). Desta forma, observando o pensamento de Freire (1996), os corpos cegos que dançam estabelecem no ato de aprender/fazer dança um ato político, criativo e transformador, pois se inscrevem em um ser/fazer/estar contínuo, incompleto, inacabado e metafórico; representativo da própria experiência humana em um diálogo presentificado na complexidade do existir.

\section{Considerações finais}

Este trabalho deseja suscitar reflexões sobre as possibilidades do corpo cego e a sua interação com a dança em uma proposta de construção da autonomia, lembrando ser este sujeito constituído de sentimentos, sonhos, desejos, emoção e razão. Um sujeito biológico, cultural, histórico, social e político que possui a sua individualidade e é também um sujeito coletivo, construído em uma rede que deve possibilitar a sua inserção como cidadão; um ser capaz, livre de discriminação na sociedade a qual pertence.
Entender o espaço próprio da dança neste processo como uma busca pessoal de construção do movimento em tempo real, pois o conhecimento não acontece apenas pelo uso da razão e sim pela interação com a emoção, possibilita compreender a importância da dança na aquisição/construção do movimento no/pelo corpo cego. A dança como atividade possível de ser realizada pelo corpo cego deve se preocupar com o estudo do corpo e suas ações, compreendendo o corpo em sua relação com o ambiente; isto acontece no fazer.

Nesta perspectiva, preocupar-se com o estudo do corpo significa compreender o corpo que se move em um determinado espaço, a interação com o corpo do outro na construção da idéia de tempo/espaço, a relação com o ambiente na busca da autonomia do corpo cego, mas com possibilidades de descobertas.

Neste sentido, praticar dança é relevante e depende da integração dos sentidos, potencializando assim as capacidades e habilidades corporais. A descoberta e a exploração do movimento estão imbricadas e são co-dependentes, sendo parte da necessidade humana de sobrevivência do indivíduo e também da permanência da espécie na terra. Para o corpo cego, esta necessidade se faz maior.

Assim, este conhecimento em dança se constrói cotidianamente com base nas experiências individuais e na interação do sujeito com o outro e com o mundo, respeitando as limitações próprias. Quanto maior for o repertório de experiências do indivíduo, maiores serão as suas chances de aprendizagem. Esta é uma relação de grandeza diretamente proporcional e a dança propicia este espaço de aprendizagem e construção de autonomia.

Pensar a dança como área de conhecimento que possibilita a utilização da criatividade, a aquisição e a produção de conhecimentos vinculados à atividade concreta, ao desenvolvimento de capacidades e de habilidades é o maior desafio deste trabalho com corpos cegos. 
É também a abertura de um espaço de atuação para profissionais comprometidos com as questões públicas que envolvem estes corpos.

Nesta perspectiva, é necessário perceber a importância da dança como atividade compartilhada que proporciona percepção do mundo, do outro e de si mesmo ao indivíduo cego. Este pode utilizar o contato físico, o fluir do movimento independente de estímulos externos, para compreender as mensagens enviadas pelo próprio corpo para a construção do movimento consciente a partir de tomadas de decisão que lhe permite a escolha de respostas, possibilitando um refinamento dos esquemas sensório-motores.

O mundo do indivíduo cego não precisa ser restrito e sem possibilidades; mesmo tendo limitação sensorial, são pessoas com capacidades e limitações como as outras e podem usufruir da dança - uma ação corporal que ocorre em tempo real possível a qualquer ser humano. Não podemos esquecer que o deficiente visual é um ser humano constituído de corpo, história, emoção, razão, sentimento, pensamento e sonhos; como tal tem o direito de usufruir dos conhecimentos humanos. A dança é uma dessas formas de conhecimento.

\section{Dance beyond vison: possibilities of the blind body}

\begin{abstract}
This article reflects on the possibilities of the blind body and its interaction with dance for the building of autonomy. Authors such as Fleming, Frazao and Lusseyran raise issues about the network built by the senses in the forming of sensory-motor images by the visually impaired. Damasio contributes to the understanding of emotion and reason. Llinás explains the construction of movement based on neuroscience. Katz's contribution of body-media theory helps with thinking of dance as cognition. In our final considerations, we see dance as a part of human knowledge and human and as a field which makes it possible for the intertwining of different kinds of knowledge, considering that human beings build themselves connecting their bodies to the environment and culture.
\end{abstract}

Keywords: visual impairment - movement - body dance - autonomy
Danza más allá de la visión: possibilidades del cuerpo ciego

\section{Resumen}

El artículo suscita reflexiones sobre las posibilidades del cuerpo ciego yla interacción con la danza en la construcción de la autonomía. Autores como Fleming, Frazão y Lusseyran apuntan a cuestiones sobre la red tejida por los sentidos en la formación de imágenes sensoriomotoras por el discapacitado visual. Damásio contribuye para el entendimiento de emoción y razón; Llinás explica la construcción del movimiento basado en la Neurociencia; Katz trae la teoría del Cuerpomedia para pensar la danza como cognición. Las consideraciones finales apuntan a la danza como parte del conocimiento humano siendo un espacio que posibilita la interacción de saberes teniendo en cuenta que el ser humano se construye en red por el imbricamiento entre cuerpo, ambiente y cultura.

Palabras-clave: discapacidad visual - movimiento cuerpo - danza - autonomía

\section{Referências}

BOBATH, B. Atividade postural reflexa anormal, causada por lesões cerebrais. São Paulo: Manole, 1978.

BRANDÃO, C. A. L. O corpo no Renascimento. In: O homem-máquina: a ciência manipula o corpo. Rio de Janeiro: Cia. das Letras, 2004. Págs. 275-297.

DAMÁSIO, A. R. O erro de Descartes: emoção, razão e o cérebro humano. Trad. Dora Vicente e Georgina Segurado. 2 ed. São Paulo: Companhia das Letras, 1996.

FLEMING, J. W. A criança excepcional. Rio de Janeiro: Francisco Alves, 1978.

FRAZÃO, M. F. Princípios básicos na educação de deficientes visuais. In: Revista Lente, Rio de Janeiro, v. 12, n. 37, abr.-jun. 1968 (Fundação para o livro do cego no Brasil).

FREIRE, Paulo. Pedagogia da Autonomia: saberes necessários à prática educativa. $31 \mathrm{ed}$. São Paulo: Paz e Terra, 1996. (Coleção Leitura).

FREUD, S. O estranho. In: História de uma neurose infantil e outros trabalhos. Trad. 
Jayme Salomão. Edição Standard Brasileira. Rio de Janeiro: Imago, 1976. v. 17.

KATZ, H. T. Um, dois, três. A dança é o pensamento do corpo. Belo Horizonte: FID, 2005.

LAKOFF, G.; JOHNSON, M. Philosophy in the flesh: the embodied mind and its challenge to western thought. New York: Basic Books, 1999.

LLINÁS, R. R. El cérebro y el mito del yo: el papel de las neuronas en el pensamiento y el comportamiento humanos. Trad. Eugenia Guzmán. $3^{a}$ reimpresión. Bogotá: Editorial Norma, 2002.

LUSSEYRAN, J. Memórias de vida e luz: autobiografia de um herói cego da Resistência Francesa. São Paulo: Antroposófica, 1995.

MERLEAU-PONTY, M. Fenomenologia da percep̧̧ão. São Paulo: Martins Fontes, 1994.

NAGY, E. et al. Postural control in athletes participating in an ironman triathlon. European Journal of applied Physiology, Springer, Verlag, v. 92, n. 04/05, p. 407-413, June 2004. Disponível em: <http://springerlink.com>. Acesso em: 18 set. 2006.

NOWILL, D. G. E eu venci assim mesmo. São Paulo: Totalidade, 1996. (Coleção Biografias, diários, memórias \& correspondências).

PIAGET, J. Formação do símbolo na criança; imitação, jogo e sonho: imagem e representação. Rio de Janeiro: LTC, 1964.
SANTAELLA, L. Culturas e artes do pósbumano: da cultura das mídias à cibercultura. São Paulo: Paulus, 2003.

SANTOS, A. Representações de pessoas cegas sobre a organização espaço-temporal tomando como referência seu próprio corpo. 1996. $84 \mathrm{f}$. Dissertação (Mestrado em Educação) - Faculdade de Educação Física, Universidade Gama Filho, Rio de Janeiro, 1996.

VIEIRA, J. A. Teoria do conhecimento e arte: formas de conhecimento - arte e ciência uma visão a partir da complexidade. Fortaleza: Expressão, 2006.

WADE, M. G.; JONES, G. The role of vision and spatial orientation in the maintenance of posture. Physical Therapy, USA, v. 77, n. 6, p. 619-628, June 1997. Disponível em: <http://web.ebscohost.com/ehost/ results?vid $=2 \&$ hid $=13 \&$ sid $=16259530-08 \mathrm{fe}-$ 43c2-9cd2-5ba4b029fc9d\%40sessionmgr2>. Acesso em: 18 set. 2006.

Recebido em: 30/03/2008

Revisado em: 28/04/2008

Aprovado em: 07/05/2008

Endereço para correspondência

clocaze@yahoo.com.br

adrianafisio07@hotmail.com 